Anna Ascenzi, Giuseppina Fattori, L'alfabeto e il catechismo. La diffusione delle scuole di mutuo insegnamento nello Stato Pontificio (1819-1830)

Pisa - Roma, Università di Macerata - Facoltà di Scienze della Formazione, 2006, $338 \mathrm{p}$.

Michel Ostenc

\title{
OpenEdition
}

Édition électronique

URL : http://journals.openedition.org/assr/5212

DOI : $10.4000 /$ assr.5212

ISSN : 1777-5825

Éditeur

Éditions de l'EHESS

Édition imprimée

Date de publication : 1 juin 2007

Pagination : 97-251

ISBN : 978-2-7132-2143-9

ISSN : 0335-5985

Référence électronique

Michel Ostenc, « Anna Ascenzi, Giuseppina Fattori, L'alfabeto e il catechismo. La diffusione delle scuole di mutuo insegnamento nello Stato Pontificio (1819-1830) », Archives de sciences sociales des religions [En ligne], 138 | avril - juin 2007, document 138-2, mis en ligne le 11 septembre 2007, consulté le 21 septembre 2020. URL : http://journals.openedition.org/assr/5212 ; DOI : https://doi.org/10.4000/assr. 5212

Ce document a été généré automatiquement le 21 septembre 2020.

(C) Archives de sciences sociales des religions 


\section{Anna Ascenzi, Giuseppina Fattori, L'alfabeto e il catechismo. La diffusione delle scuole di mutuo insegnamento nello Stato Pontificio (1819-1830)}

Pisa - Roma, Università di Macerata - Facoltà di Scienze della Formazione, 2006, 338 p.

Michel Ostenc

L'histoire de l'éducation en Italie à l'époque de la Restauration a fait l'objet de nombreuses publications ces dernières années (L. Pazzaglia (éd.), Chiesa e prospettive educative in Italia tra Restaurazione e Unificazione, Brescia, La Scuola, 1994; M. Roggero, L'alfabeto conquistato. Apprendere e insegnare in Italia tra Sette e Ottocento, Bologne, Il Mulino, 1999). Le cas des États pontificaux a été largement abordé (R. Sani, « Istruzione e istituzioni educative nella Roma pontificia (1815-1870)»; G. Tognon, «La politica scolastica nello Stato pontificio tra Restaurazione e Unificazione (1814-1860)», in L. Pazzaglia (éd.), Chiesa e prospettive educative ... op. cit., pp. 707-769, pp. 681-705); mais l'ouvrage d'Anna Ascenzi et Giuseppina Fattori s'attache au problème spécifique de la diffusion de l'enseignement mutuel dans les États du pape, après la chute de l'empire napoléonien. Ce type d'enseignement se répandit en Italie à partir de 1817. Il fut introduit par des libéraux en Lombardie pour favoriser l'alphabétisation du peuple, mais aussi afin de diffuser les idées nationales dans des territoires longtemps soumis à l'occupation étrangère. En Toscane, les écoles d'enseignement mutuel étaient destinées à soutenir les réformes économiques du Grand-duché par une meilleure formation professionnelle. À Naples, enfin, les intentions de l'abbé Antonio Scoppa étaient d'améliorer la catéchèse dans les milieux populaires. Quelles que soient les motivations de ses promoteurs, l'enseignement mutuel correspondait à une nouvelle conception de l'enfance. La diffusion du travail féminin dans l'agriculture et les manufactures créait de nouvelles exigences sociales. La multiplication des asiles de Ferrante Aporti et 
l'intérêt porté à la petite enfance par Antonio Rosmini et Raffaele Lambruschini montraient que l'Italie n'était pas insensible à cette évolution.

2 Les États pontificaux figuraient parmi ceux qui avaient le plus souffert de la domination française. Ils avaient été durement frappés par la confiscation des biens ecclésiastiques et par les prélèvements fiscaux opérés par l'administration napoléonienne. La réorganisation de l'instruction publique figurait dans les mesures de restauration de Pie VII et du cardinal Consalvi. La responsabilité des établissements scolaires à l'époque pré-révolutionnaire incombait aux évêques, mais après 1815, les gonfaloniers des communes trouvèrent dans l'enseignement mutuel les avantages d'une scolarisation moins onéreuse. En outre, l'alphabétisation des masses populaires était désormais considérée comme un facteur de croissance économique, plus qu'une menace pour l'ordre public. Si bien que les communes eurent le soutien momentané de l'administration pontificale pour organiser un enseignement mutuel, alors qu'en Toscane et en Lombardie les élites aristocratiques et bourgeoises en avaient assuré seules la promotion. Le nouveau type d'enseignement se répandit en Ombrie à l'initiative du recteur Vitale Rosi, un éducateur lié au groupe toscan des revues de Vieusseux. L'enseignement mutuel permettait aux élèves d'accéder plus rapidement à un niveau supérieur d'instruction et favorisait l'insertion des couches populaires dans le tissu économique et productif. On enseignait la lecture, l'écriture, l'arithmétique et le catéchisme dans une ambiance familiale s'inspirant des recommandations de Pestalozzi et propre à l'épanouissement du sens moral de l'enfant.

Toutefois, à l'initiative du cardinal Della Genga, le futur pape Léon XII, et du comte Vincenzo Pianciani, la commune de Spolète envisagea, dès 1820, de confier ses écoles primaires aux frères des écoles chrétiennes, une institution rattachée à la congrégation fondée par Jean-Baptiste de La Salle. Ce projet de confier les écoles publiques à des religieux échoua, et l'enseignement mutuel connut un succès particulier dans le diocèse. Les principales innovations pédagogiques de ce type d'enseignement se situaient au niveau didactique : utilisation de moniteurs, apprentissage simultané de la lecture et de l'écriture, suppression des châtiments corporels, usage du tableau noir et des cartes murales pour la reproduction des syllabaires, suppression du latin et création de classes homogènes. L'alphabétisation des populations s'en trouvait sensiblement améliorée; mais l'enthousiasme initial pour l'enseignement mutuel ne tarda pas à retomber, victime des critiques idéologiques suscitées par la place insuffisante qu'y tenait la formation morale et religieuse. Le Saint-Siège lui imposa des contrôles de plus en plus stricts et les évêques insistèrent pour que l'enseignement soit confié à des institutions religieuses. On jugeait la logique utilitaire de l'enseignement mutuel incompatible avec la conception éthico-sociale du catholicisme. La nouvelle méthode pédagogique inoculait aux élèves un système de pensée et une conception de l'ordre social très différents de ceux qui étaient en vigueur dans les États pontificaux. Les évêques des Marches s'étaient d'ailleurs opposés dès le départ à l'enseignement mutuel en dénonçant ses racines protestantes. L'intransigeance du clergé de la province s'expliquait par son opposition à toute innovation et son influence avait été confortée par son rôle déterminant dans la résistance à la domination française. L'élection de Léon XII, avec le soutien des «zelanti » en 1823, assura le succès du conservatisme. Le "pape de la Sainte-Alliance " promulgua la constitution Quod Divina Sapientia du 5 septembre 1824 qui interdisait définitivement l'enseignement mutuel dans ses États, et confia l'instruction publique aux congrégations religieuses. L'ouvrage 
d'Anna Ascenzi et Giuseppina Fattori, solidement étayé par une centaine de documents publiés en annexes, jette un nouvel éclairage sur cet aspect éducatif de la politique du cardinal Consalvi, hésitant entre les solutions libérales et les réactions conservatrices pour mécontenter finalement les tenants des unes et les partisans des autres. 